\title{
MAJOR BARRIERS ASSESSMENT OF LEAN CONSTRUCTION APPLICATION IN CONSTRUCTION PROJECTS DELIVERY
}

\author{
William Nwaki ${ }^{*}$, Emmanuel Eze ${ }^{2}$, Imoleayo Awodele ${ }^{2}$ \\ ${ }^{1}$ Building Technology Department, Delta State Polytechnic, Ozoro, Nigeria \\ ${ }^{2}$ Quantity Surveying Department, Federal University of Technology, Owerri, Imo state, Nigeria
}

(Received: February 2021 / Revised: April 2021 / Accepted: April 2021)

\begin{abstract}
The construction sector is facing challenges of meeting client's value and end-user satisfaction, and this situation is worsened by customers' dynamic demands for quality and speedy delivery without loss of value. Lean concept has been advocated to be a panacea to poor project performance, and it, however, has a high awareness level but with little implementation among construction organizations especially in developing countries including Nigeria. The purpose of this study is to assess the major barriers to lean construction application on construction project delivery, to suggest possible measures for overcoming them. A well-structured questionnaire was used to gather data from construction professionals in the south-south, Nigeria using electronic means and snowball sampling technique. Data gathered were analyzed using frequency, percentage and factor analysis. It was found that the major cluster of barriers to lean implementation are technology and knowledge barrier, leadership and management barrier, culture and complexity barrier, engagement and relationship barriers, financial barriers, and communication barriers. It was recommended that adequate management and leadership support is needed for entrenching lean construction techniques into the culture of operations of construction organisations.
\end{abstract}

Keywords: Lean construction; construction projects; barriers, lean techniques, Nigeria

\section{INTRODUCTION}

Evidence in literature has shown how critical the construction industry is on national economic growth and development. According to Nwaki and Eze (2020), the impacts of the construction industry are in the form of infrastructure and building housing provisions, wealth creation, generation of employment, and national income constructions. The construction industry is critical to economic growth of both developed and developing nation (J. G. Sarhan et al., 2017; Tezel et al., 2018). The sector is, however, facing challenges of meeting client's value and enduser satisfaction, as it is being limited in its contribution to sustainability issue (Babalola et al., 2018). The challenge is worsened by the increasing competitive pressure on construction enterprises; a resultant of customers' dynamic demands for quality and speedy delivery without loss of value (Yadav et al., 2018).

\footnotetext{
*Corresponding author's email: arkinwaki@gmail.com, Tel. +234 8037188028.
} 
There are non-value-adding activities that characterized construction project delivery. These have culminated into problems such as overruns in time and cost, poor quality and materials waste, safety issues, efficiency problems, and insufficient clients' satisfaction (Sols, 2018). A suitable way for minimizing these problems and maximizing values while removing non-value-adding events during building production is by 'producing it lean'. The lean concept is common in the manufacturing sector, and a lot of success has been recorded. Li et al. (2019) posit that since there is a lot of similarity and commonality existing between construction and manufacturing, lean thinking was introduced to solve problems related to non-value-adding activities.

In spite of the enormous benefits such as cost and time savings, better safety performance records, reduction of errors and rework, improved quality and waste reduction, better predictability of work, improved productivity, enhanced inventory management, and improved client satisfaction (Farrar et al., 2004; Ko, 2010; Mohan \& Iyer, 2005; Salem et al., 2006), recorded by leading economies in lean construction (LC) practices adoption, the concept is still at the development stage. Countries like the USA, Brazil, the UK, Chile, Denmark, South Korea, Peru, Ecuador, Finland, Venezuela, Australia, and Singapore; are the leading economics for LC adoption (Ballard \& Howell, 2003; Johansen \& Walter, 2007; Jørgensen \& Emmitt, 2008). Lean construction is a novel approach and it is still growing rapidly in recent years (Monyane et al., 2020; Shang \& Sui Pheng, 2014). This has contributed to the slow adoption and widespread interpretation and a missing rational philosophy (Alves et al., 2012; Common et al., 2000; Jørgensen \& Emmitt, 2008). Albalkhy and Sweis (2020) posit that LC is either not adequately known or fully welcomed in many developed and developing economies.

In the extant literature, studies on the challenges and limiting factors to lean implementation in many countries still exist, particularly the low adoption level of lean in construction. (Ayalew et al., 2016; A. M. Bashir et al., 2015; Cano et al., 2015; Johansen \& Walter, 2007; Olamilokun, 2015; S. Sarhan \& Fox, 2013; Shang \& Sui Pheng, 2014). There is, however, limited literature on the factors hindering LC practices implementation in the construction industry of Nigeria (Sholanke et al., 2019). Furthermore, in Nigeria, the lean concept is still not implemented on a full scale, and maximizing the full benefits of lean has remained a mirage. Construction organizations are reluctant to fully implement LC techniques which have proved to be an innovative solution to construction projects' performance problems (Nwaki \& Eze, 2020). Srinivasan et al. (2020) suggested a study that will identify the factors affecting lean principles implementation on construction projects. It is based on this that this study assessed the major barriers to LC application on construction projects delivery, to suggest possible measures for overcoming them. Nwaki and Eze (2020) claimed that LC is a panacea for poor construction project performance; this is owing to its cost-related benefits, value and relationship benefits, environmental benefits, quality improvement benefits, motivation, and productivity benefits, profitability and market benefits, time and workflow benefits, waste reduction benefits, and HS and rework reduction benefits. It is only through a full-scale adoption of the lean concepts that these benefits can be achieved.

This study implies that it will increase the knowledge of construction-based experts on the critical barriers to lean concepts and enable them to develop sustainable strategies for overcoming them. This study further advance the knowledge of construction industry participants and serve as a caution for possible drawbacks when lean have gained complete acceptance and implementation in the country. The future driving forces for LC implementation are better organized from knowledge gained from a proper understanding of the key barriers to LC. It also adds to the existing literature on LC in developing countries of the world. The lean techniques eliminate wastes in the use of labor, time and ensure the efficiency of operations in the use of materials for project delivery. Lean shortens the time of doing work, and efficient working saves money and 
energy on the project. LC application on construction projects means more money and less waste. Every stakeholder (clients, contractors, consultants, and others) are expected to feel the impact. Construction organizations would benefit from LC because it helps to reduced defects and errors, avoid over-production, eliminate waiting time, eliminate incorrect resource selection and poor use of knowledge, unnecessary transport waste, avoid excess inventory, avoid unnecessary motions, and avoid gold-plating of products. Less waste means that project could be delivered on budget and within an acceptable timeframe and meeting the functional requirements. Thus, delivering value to the client and securing their satisfaction.

\section{LITERATURE REVIEW}

\subsection{Lean Concept in Construction Industry}

What is today known as LC and practiced in the construction industry, have its origin in the manufacturing sectors, especially from Toyota production system (Bajjou \& Chafi, 2018; J. G. Sarhan et al., 2017). The eventual application of the lean philosophy in construction was premised on the successes the manufacturing sector recorded from the adoption of the lean principle and the benefits gained. Koskela (1992) was one of the pioneer authors who tried to introduce lean thinking in the construction industry. The applicability of what was called "the new production philosophy" is contained in the Stanford report produced by the author. According to Omotayo and Kulatunga (2014), after Toyota motors first introduced the lean concept to manufacturing, it has successfully been applied in the construction industry globally.

LC is a technique that focused on designing the production systems for material and time wastes minimization and value maximization (L Koskela et al., 2002). This definition of lean is the same as the main philosophy of lean in the manufacturing sector. Waste minimization and value maximization is the main philosophy of lean in the manufacturing. Scherrer-Rathje et al. (2009) state that the lean concept is a management philosophical tool aimed at reducing waste from the entire production value chain. Its application goes beyond production organizations but also along with supply chain networks. According to Hall (2019), LC is a philosophy adopted by construction organizations for a specific project being undertaken. The construction team applies lean practices and technologies to decrease time, costs, materials, and efforts, especially on a specific project at hand. According to Manrodt et al. (2008), LC adopts a systematic approach for enhancing value for clients by identifying and eliminating wastes through iteration of processes for continuous improvement in the pursuit of excellence.

Flowing from the aforementioned, LC is aimed at ensuring that the management of construction projects focuses on the minimization of waste and maximization of values for clients and project success.

\subsection{Adoption of Lean Construction}

In the Brazilian construction industry, Comelli et al. (2019) stated that adhesion to other process improvements by organizations made it difficult for LC to be implemented. Critical benefits assessment and evaluation of investment of lean is a vital and required exercise that must be done before LC principles are adopted (Campos et al., 2012). Furthermore, these efforts are needed for evaluating the investment and benefits that failed to be interpreted.

In Germany, Johansen and Walter (2007) reported that lean techniques awareness is low. Bashir et al. (2010) and Mossman (2009) in the UK observed that the implementation of lean construction practices is still limited. This situation according to Sarhan and Fox (2013) is attributed to cultural and structural barriers. Mahashabde (2016) reported that in the USA and India, the actual implementation of lean methods in construction projects has led to appreciable successes in the reduction of waste and maximization of profit. Mahashabde (2016) further found 
that, although the lean implementation is high, the participants were not aware that they were using lean techniques to minimize waste and maximize profit.

In the Moroccan construction industry, Bajjou and Chafi (2018) found that the awareness of LC among construction experts is high but the adoption level is low. In the work of Wandahl (2014), it was found that $75 \%$ (i.e. 3 out of 4 ) of the practitioners are ignorant of LC practices. This poor awareness of the lean concept was attributed to the absence of knowledge, education, and communication issues. The level of awareness of the LC techniques is also found low among construction practitioners in Turkey and African countries (Ayalew et al., 2016; Tezel \& Nielsen, 2013).

Babalola et al. (2018) found that although lean thinking awareness is growing, the adoption level remains comparatively low among construction companies. Similarly, Adegbembo et al. (2016) found that a larger proportion of the construction professionals are aware of LC techniques. 89\% of the Architects sampled in the study are familiar with LC techniques (Sholanke et al., 2019). It can be deduced from the foregoing that while the awareness level of LC is high, its adoption and implementation level is low, especially in developing countries due to certain barriers that limit its implementation among construction professionals and organizations.

\subsection{Barriers to Lean Construction}

In a single case study survey in Norway, Lodgaard et al. (2016) found that the barriers to lean implementation based on the relative percentage weighting are limited management commitment, limited leadership, lean not a daily focus, roles and responsibilities not defined, lack of motivation, chosen tools, and practices not according to best practices, chosen lean tools and practices not adding sufficient value, and lack of knowledge about lean (philosophy, principles, tools). In a related case study research among Iranian SMEs, (Moradlou \& Perera, 2017), through an interview, classified the main barriers to lean implementation into four groups; the absence of top management support, financial capability, absence of employee's skill and expertise, and organizational culture. Similarly, in the Iranian construction industry, Movaghar (2016) concluded that the most significant barriers hindering the implementation of LC in the developing countries are; lack of adequate lean awareness and understanding, culture and human attitudinal issues and, top management commitment.

In the UK, Bashir et al. (2010) carried out an in-depth analysis of barriers to LC implementation and categories the barriers into financial, educational, governmental, attitudinal, managerial, and technical barriers. In the UK, Sarhan and Fox (2013) reported that the cultural barrier is what characterized the LC implementation in the UK construction industry. Among these cultural barriers are the lack of adequate awareness and understanding, lack of management commitment, cultural and human attitudinal issues. Successful implementation of lean techniques depends on a strong lean culture supported by the management within the organization (S. Sarhan \& Fox, 2013).

In the UK, the full-scale uptake of the lean concept appears to be sparse, and contracting organizations are faced with a lot of drawbacks in the implementation of lean practices. Bashir et al. (2015) found that the major factors responsible for the drawback in implementation of lean in the UK are; changing employees' working culture, cost of implementation, lack of lean knowledge, long implementation time, complexity, lack of cooperation from employees, lack of incentives, lack of long term forecast and investment, low effort to learn, misconceptions about lean, and high expectations from management. Further analysis of these barriers to determine the nature showed that they are more related to human and technical issues. It was suggested that providing motivation such as staff training opportunities, provision of needed facilities, and 
incentives; are strategies management should adopt to overcome the barriers (A. M. Bashir et al., 2015).

In the Kingdom of Saudi Arabian (KSA) construction industry, Sarhan et al. (2018) identified twenty-two (22) barriers to LC implementation and grouped them using principal component analysis (PCA) in descending order of prevalence. These barriers are traditional practices, clientrelated barriers, technological barriers, performance and knowledge-related barriers, and financial related barriers. Bayhan et al. (2019) carried out a study aimed at providing a set of key enablers and barriers to LC implementation. 27 enablers and barriers were identified and grouped into 7 major groups, which are financial, managerial, technical, workforce, culture, government, and communication. Based on the relative mean weight of the barriers, the major components among the key categories are lack of top management support, misperception about lean practices, lack of information sharing and integrated change control, stakeholder issues in communication, failure in operational excellence, inefficiency in resource planning, and lack of organizational communication.

Oguntona et al. (2019) assessed the perception of construction professionals in South Africa regarding LC practices, and found that the major barriers to lean are poor culture among project partners, lack of good policies, the complexity of LC process, poor organizational knowledge, and lack of understanding of LC practices. The study further found that the measure for implementing LC are the appointment of lean expert/consultant, education and training of stakeholders, motivation, and commitment of stakeholders, the establishment of policy and regulatory system, and introduction of certification and measurement standards. The study of Adegbembo et al. (2016), shows some LC barriers including lack of lean awareness and understanding, lack of exposure to the need to adopt the lean concept, lack of proper training, difficulty in understanding lean concepts, weak communication among clients, consultants, and contractors, waste accepted as inevitable, and inefficient use of quality standards. The study recommended more awareness campaigns and the need to expose the workers to lean concepts training.

Ahmed and Sobuz (2019) identified and prioritized the challenges of LC implementation in the Bangladeshi construction industry and found that the highest-ranking challenges are the lack of awareness about LC, lack of skills, training, and lean techniques, unwillingness to change the existing culture, lack of management commitment, fragmented and cyclic nature of the construction project and unavailing communication between all project participants. It was recommended that more effort and focus should towards overcoming barriers such as; traditional culture and practice, stakeholder's communication and relationship, quality materials and methods, technological and performance, and knowledge barriers. Similarly, a separate study by Ahmed et al. (2020) in Bangladeshi, found that the major challenges to LC are lack of awareness and skill, poor management, traditional culture and attitude of employees, inadequate resources and equipment, and non-use of modern techniques and technologies.

In the south African construction industry, Oke et al. (2021) found that the major challenges facing the implementation of LC practices are consist of poor culture among project partners, lack of good policies, the complexity of LC process, poor organizational knowledge, lack of understanding of lean construction. The study concluded that LC revolves around attitudes, and recommended for a complete attitudinal change from the key construction participants in the dayto-day activities of LC practices. In a similar but different study, Allu and Emuze (2018) identified inadequate knowledge, lack of proactive improvement actions, and limited lean awareness as the major implementation barriers to LC in South Africa. In the UAE, Kanafani (2015) found that the two major themes of barriers to LC Implementation are lack of management commitment and lack of stakeholders' commitment. the sub-themes under these major themes 
are; lack of management commitment (absence of a qualified project management team, inefficiency in the procurement process, and lack of training, education \& development) and lack of stakeholders commitment (late involvement in the supply chain, lack of client \& consultant engagement in LC, and lack of proper risk assessment \& management).

Forty-one (41) major barriers to LC were selected from the reviewed literature and summarised in table 1 .

\section{METHODS}

This study adopted a questionnaire survey approach of construction professionals in the southsouth region of Nigeria. The questionnaire is suitable for covering a large area, and it is economical and fast in data collection. The target participants were architects, engineers, quantity surveyors, and builders; who have at least 5 years of working experience in the industry and are engaged in active construction sites at the time of this study. Furthermore, they were required to have knowledge of LC techniques. These criteria were to ensure unbiased and quality data are gathered from the participants. The south-south region is made of six states (Akwa Ibom, Bayelsa state, Cross River, Delta, Edo, and Rivers states), and the population of the professionals in these states was obtained from the previous study (Otali et al., 2020), of 1252. This sample population is equivalent to 197 sample sizes from Krejcie and Morgan (1970) sample size determination table.

The questionnaire has two sections and the first section collected data on the survey participants' basic information. The second section gathered data on the barriers to LC techniques application on construction project delivery. Based on the level of importance of the 41 selected barriers from the literature review, the participants were required to rate the barriers on a 5-point Likert scale $(1=$ lowest scale, $5=$ highest scale). The procedure for data collection was through the use of snowball sampling techniques and personal delivery from the researchers and by email. The snowball sampling technique is dependent on referrals and it can increase the sample size (Atkinson R \& J, 2001; Heckathorn, 2011). According to Nwaki and Eze (2020), the electronic means of questionnaire survey is environmentally friendly, reduces the volume of hardcopy questionnaires.

At the end of survey participants' sampling, a total of 161 useable responses were received and these represent a responses rate of $81.73 \%$. The response rate of $81.73 \%$ is high because followup calls were put across to the participants over the 14 weeks duration of the study. The breakdown of the $161(81.73 \%$ ) gathered responses by state are (Akwa Ibom=16(9.94\%), Bayelsa state $=14(8.7 \%)$, Cross river $=27(16.77 \%)$, Delta $=39(24.22 \%), E d o=29(18.01 \%)$, and River state $=36(22.36 \%)$. 


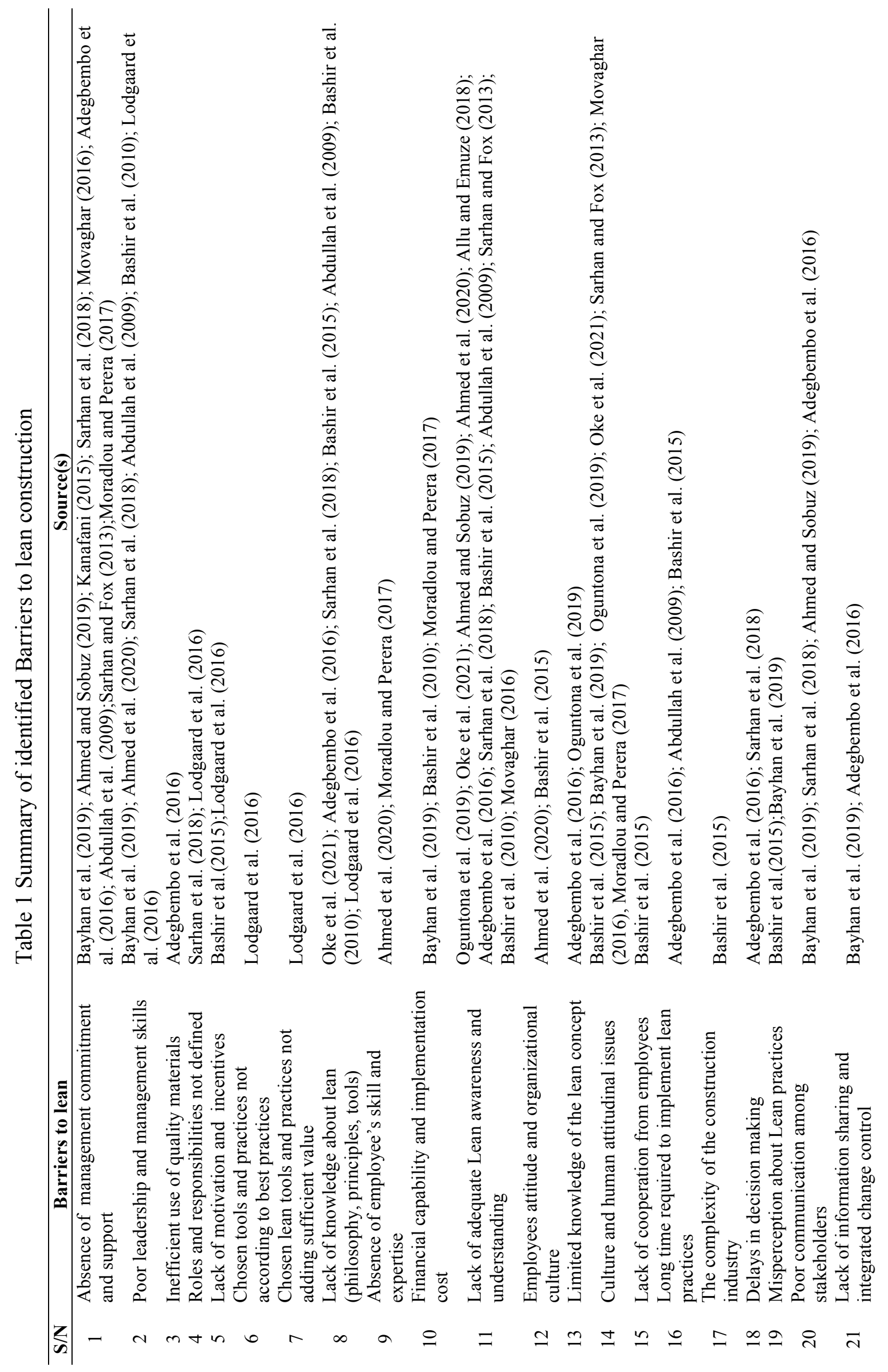




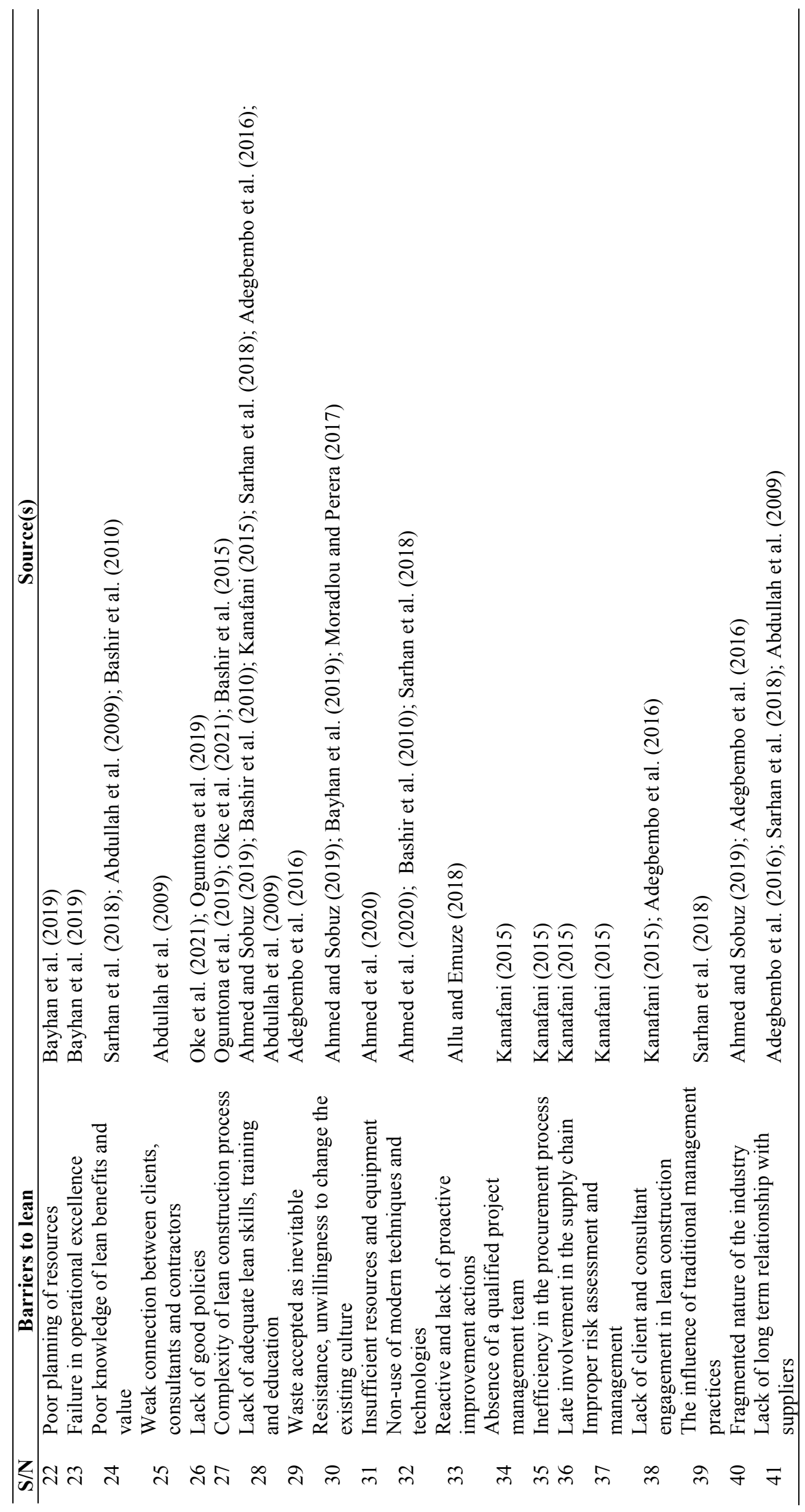


The collected data were subjected to a reliability test using the Cronbach alpha test. An alpha value of 0.957 was obtained for the assessed variables. This shows a very high level of reliability of the research instrument. Frequencies and percentages were used to analyze the basic background information of the respondents. Factor analysis (FA) was used to analyze the data gathered on the barriers to LC application on construction projects. The FA used principal component analysis (PCA) with varimax rotation as the method of data extraction. Factors analysis was aimed at reducing the variables into a cluster of a manageable and cohesive proportion of different construct. The entire methodological flow is represented in Figure 1.

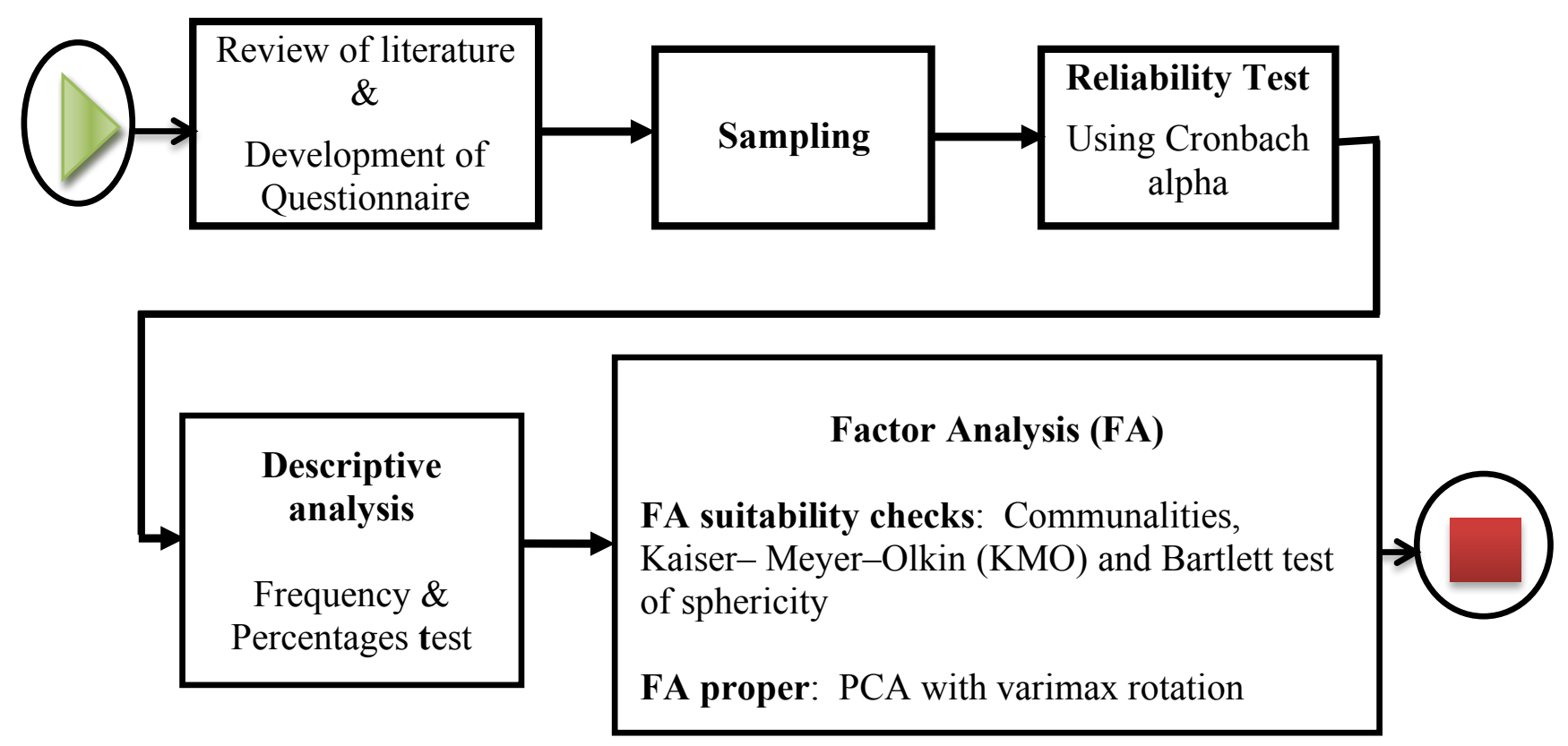

Figure 1 Methodology flow chart

\section{RESULTS AND DISCUSSION}

\subsection{Basic Information of Respondents}

The analysis of the basic information of the respondents shows that the survey participants from the private organizations are more by $57.14 \%$, and they are followed by those from the public organizations by $42.86 \%$. By profession, a good number of the participants are Engineers (31.68\%), followed by Architects (30.43\%), then Quantity Surveyors (24.22\%), and lastly, Builders (13.66\%). This shows a good mix of the key professionals' employees of construction organizations. The average working experience of the participants is 13.48 years and this fell within the modal and median class of range $11-15 y$ years. With $36.02 \%$ and $29.81 \%$ having bachelor degree (BSc./B.Tech) and Master's degree (MSc./M.Tech.) respectively as their highest academic qualifications, shows that they are educationally qualified to make a meaningful contribution to the subject of this study. Finally, in terms of professional members, $91.30 \%$ of the respondents are corporate members of their various professional bodies, and only $8.7 \%$ are probationers of their professional bodies. This indicates that highly professional and experienced participants took part in this survey.

\subsection{Major Barriers to Lean Construction}

Prior to carrying out the factor analysis, the factorability and adequacy of the collected data for the analysis were done. This was achieved regarding the sample size, the number of variables, commonalities, Kaiser-Meyer-Olkin (KMO) measure of sampling adequacy, and Bartlett's test 
of sphericity. With regards to the number of variables and sample size; the 41 barriers selected from the literature are adequate and this is based on the understanding that there is yet to be an agreement regarding what number of variables is suitable for factor analysis. Also, the sample size of 161 is adequate for factor analysis and this is premised on the suggestions of (Hair et al., 2010; Pallant, 2007; Tabachnick \& Fidell, 2007).

Table $2 \mathrm{KMO}$ and Bartlett's Test for Lean Construction Barriers

\begin{tabular}{llc}
\hline Kaiser-Meyer-Olkin Measure of Sampling Adequacy. & Approx. & Chi- \\
& Square & 5006.914 \\
Bartlett's Test of Sphericity & df & 820 \\
& Sig. & 0.0000 \\
\hline
\end{tabular}

The maximum and minimum communalities values for the variables are 0.832 and 0.501 respectively and with an average of 0.694 . The average communality is above 0.60 , and the sample size becomes meaningless in determining sample size adequacy for FA (Pallant, 2007; Taherdoost et al., 2014). Furthermore, variables with a communalities figure of greater than 0.5 fit well in the construct with other variables (Eze et al., 2018). Furthermore, with the KMO value of 0.869 which is above the cut-off score of 0.50 (Field, 2005; Hair et al., 2010) and the Bartlett test with a chi-square value of $5006.914, \mathrm{df}=820$, and p-value of 0.000 (see Table 2), it can be said that the variables are suitable and adequate for factor analysis.

\subsubsection{Factor analysis: Principal component analysis (PCA) and factor extraction}

Through the utilization of principal component analysis (PCA) with varimax rotation as the method of extraction, the factor analysis was executed. Six factors were extracted with eigenvalues of greater than 1.0, based on the Total Variance Explained (TVE). The 6 factors extracted accounts for over $50 \%$ of the total cumulative variance. This is in line with the proposal from previous studies (Hair et al., 2010; Pallant, 2007; Stern, 2010) (see table 3).

Table 3 Total Variance Explained (TVE) of barriers to lean construction

\begin{tabular}{cccccccccc}
\hline \multirow{2}{*}{ Component } & \multicolumn{3}{c}{ Initial Eigenvalues } & \multicolumn{3}{c}{$\begin{array}{c}\text { Extraction Sums of } \\
\text { Squared Loadings }\end{array}$} & \multicolumn{3}{c}{$\begin{array}{c}\text { Rotation Sums of } \\
\text { Squared Loadings }\end{array}$} \\
\cline { 2 - 10 } & \multirow{2}{*}{ Total } & $\begin{array}{c}\text { \% of } \\
\text { Variance }\end{array}$ & $\begin{array}{c}\text { Cum. } \\
\text { \% }\end{array}$ & Total & $\begin{array}{c}\text { \% of } \\
\text { Variance }\end{array}$ & $\begin{array}{c}\text { Cum. } \\
\text { \% }\end{array}$ & Total & $\begin{array}{c}\text { \% of } \\
\text { Variance }\end{array}$ & $\begin{array}{c}\text { Cum. } \\
\text { \% }\end{array}$ \\
\hline 1 & 15.84 & 38.63 & 38.63 & 15.84 & 38.63 & 38.63 & 5.62 & 13.72 & 13.72 \\
2 & 3.19 & 7.77 & 46.41 & 3.19 & 7.77 & 46.41 & 4.40 & 10.74 & 24.45 \\
3 & 2.22 & 5.42 & 51.83 & 2.22 & 5.42 & 51.83 & 4.29 & 10.45 & 34.91 \\
4 & 1.87 & 4.55 & 56.38 & 1.87 & 4.55 & 56.38 & 3.99 & 9.74 & 44.64 \\
5 & 1.54 & 3.77 & 60.15 & 1.54 & 3.77 & 60.15 & 2.73 & 6.65 & 51.29 \\
6 & 1.33 & 3.25 & 63.40 & 1.33 & 3.25 & 63.40 & 2.71 & 6.61 & 57.91 \\
\hline
\end{tabular}

In the Rotated Component Matrix (RCM), table 4, only variables with a factor loading of greater than 0.50 were extracted (retained) and this is based on the (Spector, 1992) submission. The 6 major components contain items with a factor loading that explained much of the variance than the remaining components. 


\subsubsection{Categorization and extractor factor discussion}

Categorization is determined by the examination of the critical and latent characteristics of the items loading under the components. Where it is difficult to secure a befitting name for components, consideration is given to the items with the highest factor loading under the component under consideration.

In the RCM (Table 4), 8 items were loading under the first components and they account for $38.63 \%$ of the total variance explained of the extracted variables. These items are non-use of modern techniques and technologies, lack of adequate lean skills, training and education, poor knowledge of lean benefits and value, lack of adequate lean awareness and understanding, late involvement in the supply chain, improper risk assessment and management, fragmented nature of the industry, and inefficiency in the procurement process. After a critical examination of the items, the component was named 'Technology and Knowledge barriers'. The construction industry of this day is technology-driven and knowledge is an asset of organizations. The poor utilization of technology in construction has impacted on cost and time of project delivery, thereby leading to more wastage. This is, however, against the philosophy of LC.

Table 4 Rotated Component Matrix (RCM) of lean construction barriers

\begin{tabular}{|c|c|c|c|c|c|c|}
\hline \multirow{2}{*}{ Variables } & \multicolumn{6}{|c|}{ Component } \\
\hline & 1 & 2 & 3 & 4 & 5 & 6 \\
\hline \multirow{3}{*}{ Non-use of modern techniques and technologies } & 0.77 & & & & & \\
\hline & 4 & & & & & \\
\hline & 0.74 & & & & & \\
\hline \multirow[t]{2}{*}{ Lack of adequate lean skills, training and education } & 1 & & & & & \\
\hline & 0.69 & & & & & \\
\hline \multirow[t]{2}{*}{ Poor knowledge of lean benefits and value } & 4 & & & & & \\
\hline & 0.67 & & & & & \\
\hline \multirow{2}{*}{ Lack of adequate Lean awareness and understanding } & 0 & & & & & \\
\hline & 0.57 & & & & & \\
\hline \multirow[t]{2}{*}{ Late involvement in the supply chain } & 6 & & & & & \\
\hline & 0.53 & & & & & \\
\hline \multirow[t]{2}{*}{ Improper risk assessment and management } & 9 & & & & & \\
\hline & 0.52 & & & & & \\
\hline \multirow[t]{2}{*}{ Fragmented nature of the industry } & 7 & & & & & \\
\hline & 0.50 & & & & & \\
\hline \multirow[t]{2}{*}{ Inefficiency in the procurement process } & 4 & & & & & \\
\hline & & 0.74 & & & & \\
\hline \multirow[t]{2}{*}{ Lack of client and consultant engagement in lean construction } & & 5 & & & & \\
\hline & & 0.72 & & & & \\
\hline \multirow[t]{2}{*}{ Lack of long term relationship with suppliers } & & 8 & & & & \\
\hline & & 0.69 & & & & \\
\hline \multirow[t]{2}{*}{ Weak connection between clients, consultants and contractors } & & 3 & & & & \\
\hline & & 0.59 & & & & \\
\hline \multirow[t]{2}{*}{ Waste accepted as inevitable } & & 5 & & & & \\
\hline & & 0.54 & & & & \\
\hline \multirow[t]{2}{*}{ Long time required to implement lean practices } & & 9 & & & & \\
\hline & & & 0.80 & & & \\
\hline \multirow[t]{2}{*}{ Organizational culture and employees attitude } & & & 3 & & & \\
\hline & & & 0.77 & & & \\
\hline \multirow[t]{2}{*}{ Complexity of lean construction process } & & & 5 & & & \\
\hline & & & 0.62 & & & \\
\hline \multirow{2}{*}{ Resistance, unwillingness to change the existing culture } & & & 5 & & & \\
\hline & & & 0.59 & & & \\
\hline \multirow[t]{2}{*}{ Lack of good policies } & & & 3 & & & \\
\hline & & & 0.53 & & & \\
\hline Failure in operational excellence & & & 0 & & & \\
\hline
\end{tabular}




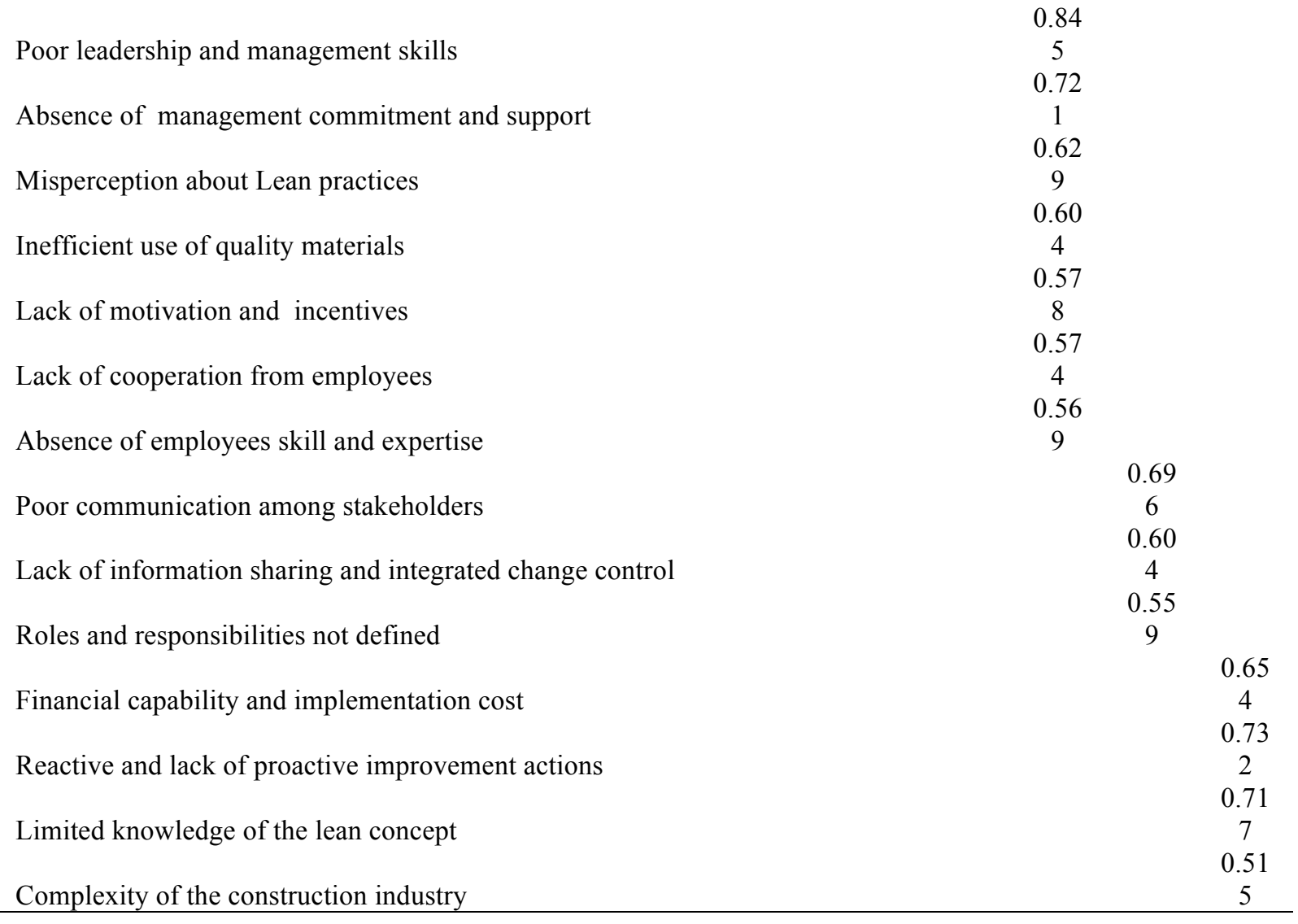

LC implementation in the construction industry of most nations has suffered a serious setback because of a lack of the basic skills, education, and training on the concepts. Training and education improve knowledge such as awareness and understanding, knowledge of benefits of lean, among others. This is well documented in the extant construction management literature (Shakil Ahmed et al., 2020; Shakil Ahmed \& Sobuz, 2019; Allu \& Emuze, 2018; A. Bashir et al., 2010; A. M. Bashir et al., 2015; Moradlou \& Perera, 2017; Movaghar, 2016; Oguntona et al., 2019; Oke et al., 2021; S. Sarhan \& Fox, 2013)

The adoption level of modern technologies that accelerate construction work and enhance communication is low, and this impedes the communication of LC techniques (Shakil Ahmed et al., 2020). Lack of the basic skills and knowledge on how to use modern technological tools like BIM is a challenge that impacts the successful application of lean principles (J. Sarhan et al., 2018). Zhang et al. (2018) found that BIM which is an innovative technology can be utilized to enhance project performance. BIM helps to detect clashes that can result to rework, thus, eliminating wastages in construction materials, time and cost. The adoptions of LC principles using computer simulation have been found to reduce different types of waste (Nikakhtar et al., 2015). One of the most critical barriers to LC is poor awareness and understanding, and poor knowledge of the benefits and value of the concept (Allu \& Emuze, 2018; S. Sarhan \& Fox, 2013). According to Ahmed and Sobuz (2019), technological and knowledge barriers were some of the barriers to LC implementation that requires adequate focus towards eliminating because of the level of impact they have on LC application on construction projects.

The second component has 5 items and accounts for about $7.77 \%$ of the total variance explained. After an examination of the variables loaded under this component, it was named 'Engagement and relationship barriers'. The component is comprised of lack of client and consultant engagement in LC, lack of long-term relationship with suppliers, weak connection between clients, consultants, and contractors, waste accepted as inevitable and long time required 
implementing lean practices. Stakeholders' engagement and relationship issues hinder the implementation of LC practice on construction projects. The implementation of innovative construction management techniques like the lean concept requires the buy-in of all stakeholders and a smooth relationship.

The engagement and relationship barrier reported in this study is in line with the findings of (Shakil Ahmed \& Sobuz, 2019; Kanafani, 2015). Kanafani (2015) found that lack of client and consultant engagement in LC is stakeholders' barrier to lean concept. Stakeholder communication and relationship was identified by Ahmed and Sobuz (2019) are barriers to LC. When stakeholders are properly engaged, they will get details of what they are up against. Proper engagement of project stakeholders and good working relationships are a panacea for effective information sharing and smooth workings toward the delivery of construction projects. Ahmed et al. (2020) found that stakeholders' communication and relationships are challenges that need to be overcome in the implementation of LC.

In the $3^{\text {rd }}$ component, 5 items are loaded under it, and they account for $5.42 \%$ of the total variance explained. These five items are organizational culture and employee attitude, the complexity of LC process, resistance, unwillingness to change the existing culture, lack of good policies, failure in operational excellence. Following a cursory look at these items that loaded under this component, it was 'Culture and complexity barriers'. Organizational and employees' culture and the complexity of the construction processes make it difficult for construction organizations to reap the full benefits of LC. Attitudinal issues regarding new techniques are well document in literature (Shakil Ahmed et al., 2020; Shakil Ahmed \& Sobuz, 2019). The culture was found among the key issues that impede the implementation of the lean concept on construction projects (Bayhan et al., 2019). Cultural issues and the complexity of the lean construction process, absence of good policies that support LC; were found by (Oke et al., 2021) as the major factors impeding LC implementation in the construction industry of South Africa. The LC application is not as straightforward as it seems. It involves conscious efforts backed up by a disciplined and dedicated lean team to achieve the lean objectives of waste reduction and value maximization. Resistance and unwillingness to change by some critical stakeholders is another factor that causes drawbacks to LC application on construction projects. Over satisfaction with the existing method of project, delivery is another factor that impedes the use of modern waste minimization techniques like LC. This supports the findings of Ahmed and Sobuz (2019).

The fourth component was named 'leadership and management barriers', after a critical examination of the items loaded under it. This component has seven items and accounted for about $4.55 \%$ of the total variance explained. These items are poor leadership and management skills, absence of management commitment and support, misperception about lean practices, inefficient use of quality materials, lack of motivation and incentives, lack of cooperation from employees, absence of employee skill and expertise. Leadership and management commitment and support are key to entrenching the best practices in the construction industries of nations. A driving force to lean implementation is leadership style and management support. Poor management support is well document in the extant literature as a critical barrier to lean concept (Shakil Ahmed \& Sobuz, 2019; Lodgaard et al., 2016; Moradlou \& Perera, 2017; Movaghar, 2016; S. Sarhan \& Fox, 2013). The most important barrier to innovation adoption in any industry is leadership and management support. Lodgaard et al. (2016), Ahmed and Sobuz (2019), and Sarhan and Fox (2013) found that insufficient commitment from management and poor leadership are among the major barriers to LC. Moradlou and Perera (2017) and Movaghar (2016) also reported that the lack of top management support is one of the key factors that impede LC. It is the responsibility of management and leadership to provide the enabling environment for the implementation of the lean concept. This will be possible when they invest in it, motivate the workforce by way of increasing their knowledge, skills, and understanding of the concept. Also, 
they are responsible for the provision of the needed tools, equipment, and technologies that drive LC on construction projects.

Three items loaded under the $5^{\text {th }}$ component and account for $3.77 \%$ of the total variance explained. These three items are poor communication among stakeholders, lack of information sharing and integrated change control, roles and responsibilities not defined. This component was named 'Communication barriers' based on the examination of the items loading under it. It is through communication that new knowledge and concepts are shared. Effective communication improves stakeholders' engagement levels and relationships. The lack of effective communication is a barrier to LC. Unavailing communication between all project participants was reported by Ahmed and Sobuz (2019) are major barriers to LC. One of the major categories of lean barriers identified by (Bayhan et al., 2019), is communication. Communication issues among stakeholders and the lack of effective organizational communication is a major limiting factor to LC practices in construction projects. Weak communication among clients, consultants, and contractors were among the barriers to lean identified by (Adegbembo et al., 2016). Communication plays a critical role in construction project delivery. Poor and ineffective communication has been blamed for so many problems facing construction projects. Poor communication is linked to disputes, claims, errors, rework, safety issues, cost overruns, qualities issues, among others. For LC to be successfully implemented, effective communication and information sharing are key success factors in project development.

Four items were loaded under the 6th component and it accounts for $3.25 \%$ of the total variance explained and the $63.40 \%$ cumulative variance of the extracted factors. The items loaded under this component are; financial capability and implementation cost, reactive and lack of proactive improvement actions, limited knowledge of the lean concept, and complexity of the construction industry. These items were closely related to cost, and this led to the naming of the component as 'Financial barriers'. Finance is an important driver for innovative techniques in the construction industry of nations. The lack or insufficiency of finance means that a lot of innovative tools and techniques will not be applied to construction. This result is in line with the findings of previous literature (A. Bashir et al., 2010; Bayhan et al., 2019; Moradlou \& Perera, 2017; J. Sarhan et al., 2018). Moradlou and Perera (2017) found that financial capability is a major barrier to LC implementation in construction. Bashir et al. (2010) in the UK found that financial issues are among the major barriers to LC implementation. Sarhan et al. (2018) and Bayhan et al. (2019) also found that financial related barrier is among the major categories of LC implementation barriers. Finance is the 'life blood' and the 'oxygen' of the construction project. Quality materials and labor and equipment, technologies are procured using finance. The lack of or inadequacy of it could lead to project abandonment, claims, and disputes.

From figure 1, it can be seen that technology and knowledge barriers are the most critical barriers to LC, and this is closely followed by leadership and management barrier, then culture and complexity barrier, engagement and relationship barrier, financial barriers, and lastly communication barriers. These reflect the major barriers that need to be overcome by construction organizations for the full potentials benefits of LC techniques to be achieved. 


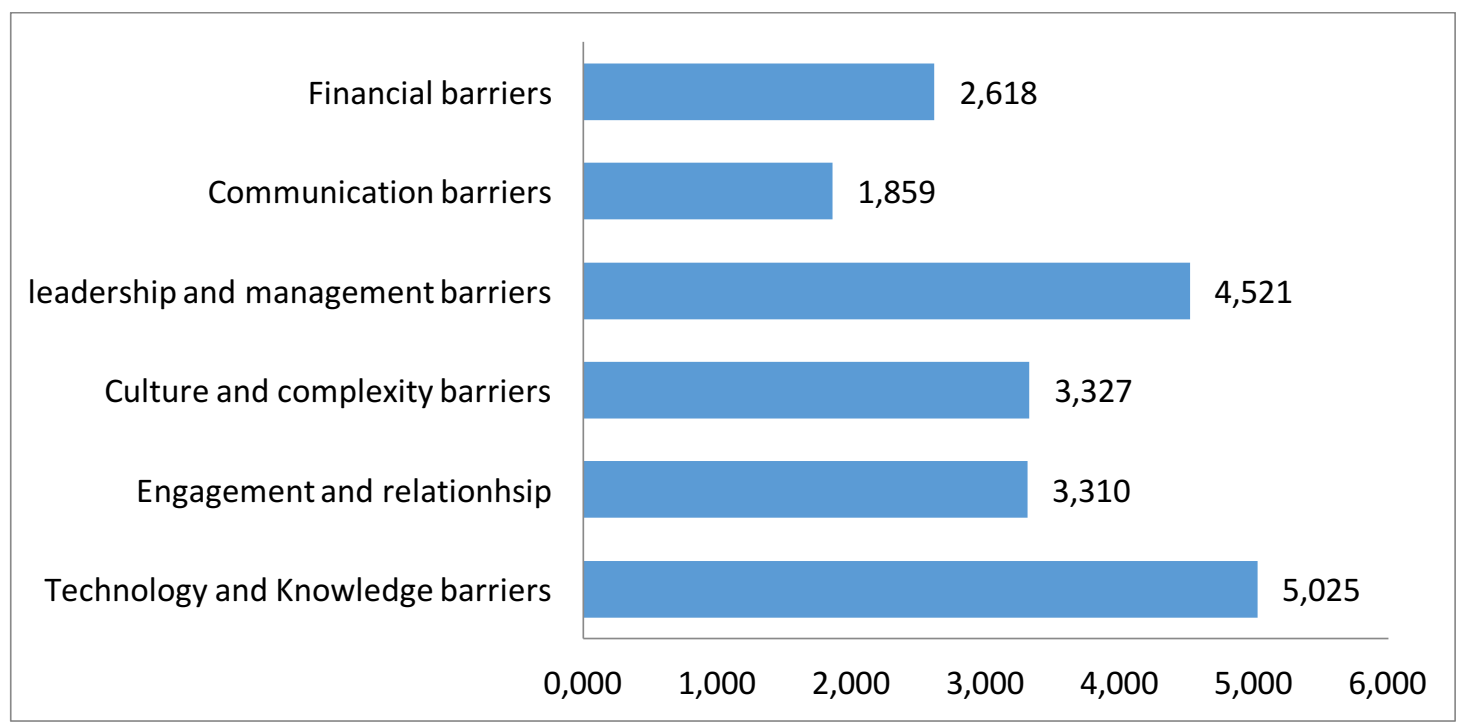

Figure 1 Weighting of factor loading

From the major cluster of barriers of LC found in this study, the following recommendations were made;

- Adoption of modern technology for running the affairs of construction projects. Construction organizations should accept IT-based technology to avoid wastages and loss of values. Management has a role to play in seeking collaboration in areas of technology. Furthermore, knowledge-building activities should be entrenched; this will increase awareness and understanding of the lean concept among construction stakeholders.

- There should be sufficient engagement and a balanced and healthy relationship between the clients, consultants, contractors, and other stakeholders. This will improve communications and understanding of new concepts like lean the approach. Opposition to lean implementation is minimized or even eliminated when there are healthy relationships among stakeholders.

- LC practices should be made an integral part of the functioning and operations of the construction organizations. This will improve the adoption level of LC and better project performance.

- Adequate management support and leadership are key to the successful implementation of the lean concept in the construction industry. Support for technology, training, and making lean part of the organizational culture is a driving force for speedy diffusion of the lean concept among construction professionals and other employees.

- Efficient and effective communication should be provided for the smooth transfer of lean ideas within an organization. Management has a role to play in ensuring smooth information sharing and data dissemination.

- Finance is the 'life blood' of any project; no project can succeed without adequate financing. Following the Lean techniques judiciously is costly and time-consuming, and requires a lot of commitment and resources. LC practices should be seen as an investment with huge benefits.

\section{CONCLUSION}

This study was set out to assess the major barriers to LC application on construction project delivery, to suggest possible measures for overcoming the barriers. By utilizing a well-structured questionnaire, through electronic means and snowball sampling techniques, data were collected from construction professionals in the south-south, Nigeria. Appropriate analytical tools were adopted and the study was able to make meaningful findings. 
The study found that the major barriers to LC are technology and knowledge barrier, leadership and management barrier, culture and complexity barrier, engagement and relationship barrier, financial barriers, and communication barriers. The existence of these barriers in the construction industry of Nigeria and other developing countries of Africa have been blamed for the persistence of time and other resource wastages and loss of value that characterized the delivery of construction projects. These are also amongst the leading causes of time and cost overruns, quality degradation, rework, materials waste, safety issues, efficiency problems, and claims and disputes.

A critical driver of innovative construction methods is the use of modern technology and knowledge. Management and leadership and organizational culture influence the successful adoption of LC practices in the construction industry. LC is an innovative technique for managing organizational and/or project resources so that non-value-added efforts are avoided in the quest to maximize value and better project performance.

These key barriers to LC will enable managers of construction organizations and projects to better prepare for the challenges ahead, especially as they have to do with the reduction of wastages and maximization of projects and value. This study adds to the few existing bodies of knowledge on LC, especially in a developing country including Nigeria.

\section{LIMITATION AND FUTURE RESEARCH DIRECTION}

This study was carried out in the south-south region of Nigeria, and this is a critical limitation toward the generalization of the findings. In addition to the geographical boundary, the number of variables assessed, the sample size, and the sampling method are other limitations of the study. A similar study could be carried out in other zones of Nigeria or developing countries, especially of Africa, with similar social-economic dynamics like Nigeria. Such a study should consider larger sample size and number of variables and other sampling techniques. This will make data available for comparison purposes. Furthermore, a detailed investigation should be carried out on technology-specific barriers to lean adoption in other zones or countries. In addition, leadership and management are key drivers of innovation, what management style is suitable for lean concept implementation in construction? This question requires an answer and this is will only be possible through a survey. Rework has come to stay with the construction industry, and it has been identified as a major cause of poor project performance, especially as it ensures that the time, cost, and quality objectives of projects are unsatisfactory. A study to develop a lean framework for managing rework could be embarked upon.

\section{REFERENCES}

Abdullah, S., Razak, A., Bakar, A., Hassan, A., \& Sarrazin, I. (2009). Towards producing best practice in the Malaysian construction industry: the barriers in implementing the Lean Construction Approach. In Building. http://eprints.usm.my/16097/

Adegbembo, F. T., Bamisaye, O. P., \& Aghimien, D. O. (2016). Assessment of lean construction practice in the Nigerian construction industry. Joint International Conference (JIC) on 21st Century Human Habitat: Issues, Sustainability and Development, March.

Ahmed, Shakil, Hossain, M. M., \& Haq, I. (2020). Implementation of lean construction in the construction industry in Bangladesh: awareness, benefits and challenges. International Journal of Building Pathology and Adaptation, 39(2), 368-406. https://doi.org/10.1108/IJBPA-04-2019-0037

Ahmed, Shakil, \& Sobuz, M. H. R. (2019). Challenges of implementing lean construction in the construction industry in Bangladesh. Smart and Sustainable Built Environment, 9(2), 174 
207. https://doi.org/10.1108/SASBE-02-2019-0018

Albalkhy, W., \& Sweis, R. (2020). Barriers to adopting lean construction in the construction industry: a literature review. In International Journal of Lean Six Sigma (Vol. 12, Issue 2, pp. 210-236). https://doi.org/10.1108/IJLSS-12-2018-0144

Allu, E. L. A., \& Emuze, F. (2018). Perceptions of Lean Implementation: A Case Study of A South African Construction Client. 10TH CIDB POSTGRADUATE CONFERENCE, March, 315-322.

Alves, T. D. C. L., Milberg, C., \& Walsh, K. D. (2012). Exploring lean construction practice, research, and education. Engineering, Construction and Architectural Management, 19(5), 512-525. https://doi.org/10.1108/09699981211259595

Atkinson R, \& J, F. (2001). Accessing Hidden and Hard-to-Reach Populations: Snowball Research Strategies. Social Research Update, 33. http://sru.soc.surrey.ac.uk/SRU33.html

Ayalew, T., Zakaria, D., \& Lafhaj, Z. (2016). The Future of Lean Construction in Ethiopian Construction Industry. International Journal of Engineering Research, 5(02), 107-113.

Babalola, O. D., Ibem, E. O., \& Ezema, I. C. (2018). Assessment of awareness and adoption of lean practices in the Nigerian building industry. International Journal of Civil Engineering and Technology, 9(13), 1626-1640.

Bajjou, M. S., \& Chafi, A. (2018). Lean construction implementation in the Moroccan construction industry: Awareness, benefits and barriers. Journal of Engineering, Design and Technology, 16(4), 533-556. https://doi.org/10.1108/JEDT-02-2018-0031

Ballard, G., \& Howell, G. A. (2003). Lean project management. Building Research and Information, 31(2), 119-133. https://doi.org/10.1080/09613210301997

Bashir, A. M., Suresh, S., Oloke, D. A., Proverbs, D. G., \& Gameson, R. (2015). Overcoming the Challenges facing Lean Construction Practice in the UK Contracting Organizations. International Journal of Architecture, Engineering and Construction, 4(1). https://doi.org/10.7492/ijaec.2015.002

Bashir, A., Suresh, S., Proverbs, D. G., \& Gameson, R. (2010). Barriers towards the sustainable implementation of lean construction in the United Kingdom construction organisations. Arcom Doctoral Workshop, June.

Bayhan, H. G., Demirkesen, S., \& Jayamanne, E. (2019). Enablers and Barriers of Lean Implementation in Construction Projects. IOP Conference Series: Materials Science and Engineering, 471(2). https://doi.org/10.1088/1757-899X/471/2/022002

Campos, I., Oliveira, D. De, Carneiro, S., Carvalho, A. De, \& Neto, J. (2012). Relation between the sustainable maturity of construction companies and the philosophy of lean construction. Proceeding of 20th Annual Conference of IGLC.

Cano, S., Delgado, J., Botero, L., \& Rubiano, O. (2015). Barriers and success factors in lean construction implementation-survey in pilot context. Proceedings of IGLC 23 - 23rd Annual Conference of the International Group for Lean Construction: Global Knowledge - Global Solutions, 2015-January.

Comelli, M. L., de Carvalho, Y. M. V., Marinho, R. C., Cândido, L. F., \& de Paula Barros Neto, J. (2019). Assessing the level of implementation of lean construction: An audit protocol. 27th Annual Conference of the International Group for Lean Construction, IGLC 2019. https://doi.org/10.24928/2019/0202

Common, G., Johansen, E., \& Greenwood, D. (2000). A survey of the take-up of lean concepts among UK construction companies. In Proceedings of the 8th International Group for Lean Construction Annual Conference. Brighton, United Kingdom.

Eze, E., Idiake, J. E., \& Ganiyu, B. O. (2018). Analysis of Rework Risk Triggers in the Nigerian Construction Industry. Organization, Technology and Management in Construction: An International Journal. https://doi.org/10.2478/otmcj-2018-0008

Farrar, J. M., Abourizk, S. M., \& Mao, X. (2004). Generic implementation of lean concepts in 
simulation models. Lean Construction Journal, 1(1).

Field, A. (2005). Discovering Statistics Using SPSS (Introducing Statistical Methods S.). In Methods (Vol. 3rd). SAGE Publications. http://www.amazon.com/dp/0761944524

Hair, J., Black, W., Babin, B., \& Anderson, R. (2010). Multivariate Data Analysis: A Global Perspective. In Multivariate Data Analysis: A Global Perspective.

Hall, R. (2019). The Benefits Of Lean Construction. White Cap News. https://news.whitecap.com/the-benefits-of-lean-construction/

Heckathorn, D. D. (2011). Comment: Snowball versus respondent-driven sampling. In Sociological Methodology (Vol. 41, Issue 1, pp. 355-366). https://doi.org/10.1111/j.14679531.2011.01244.x

Johansen, E., \& Walter, L. (2007). Lean construction: Prospects for the German construction industry. Lean Construction Journal, 3(1), 19-32.

Jørgensen, B., \& Emmitt, S. (2008). Lost in transition: The transfer of lean manufacturing to construction. Engineering, Construction and Architectural Management, 15(4), 383-398. https://doi.org/10.1108/09699980810886874

Kanafani, J. (2015). Barriers to the implementation of lean thinking in the construction industry - the case of UAE. University of Leicester.

Ko, C. H. (2010). Application of lean production system in the construction industry: An empirical study. Journal of Engineering and Applied Sciences, 5(2), 71-77. https://doi.org/10.3923/jeasci.2010.71.77

Koskela, L, Ballard, G., Howell, G., \& Tommelein, I. (2002). The foundations of lean construction. In Design and construction: building in value (pp. 211-226). Butterworth Heinemann.

https://www.thenbs.com/PublicationIndex/documents/details?Pub=BUTTERWORTH\&DocI $\mathrm{d}=264422$

Koskela, Lauri. (1992). Application of the New Production Philosophy to Construction. https://www.leanconstruction.org/media/docs/Koskela-TR72.pdf

Krejcie, R. V., \& Morgan, D. W. (1970). Determining Sample Size for Research Activities. Educational and Psychological Measurement, 30(3), 607-610. https://doi.org/10.1177/001316447003000308

Li, X. K., Wang, X. M., \& Lei, L. (2019). The application of an ANP-Fuzzy comprehensive evaluation model to assess lean construction management performance. Engineering, Construction and Architectural Management, 27(2), 356-384. https://doi.org/10.1108/ECAM-01-2019-0020

Lodgaard, E., Ingvaldsen, J. A., Gamme, I., \& Aschehoug, S. (2016). Barriers to Lean Implementation: Perceptions of Top Managers, Middle Managers and Workers. Procedia CIRP, 57, 595-600. https://doi.org/10.1016/j.procir.2016.11.103

Mahashabde, V. (2016). Comparison of Lean Construction in India and United States of America [Western Kentucky University]. In Masters Theses \& Specialist Projects. https://digitalcommons.wku.edu/theses/1728

Manrodt, K. B., Vitasek, K., \& Thompson, R. H. (2008). Lean practices in the supply chain, Jones Laselle 2008 Report. https://www.scribd.com/document/129675634/Lean-Practices-InSupply-Chain

Mohan, S. B., \& Iyer, S. (2005). Effectiveness of lean principles in construction. 13th International Group for Lean Construction Conference: Proceedings, 421-429.

Monyane, T., Emuze, F., Awuzie, B., \& Crafford, G. (2020). Challenges to Lean Construction Implementation in South Africa. In The Construction Industry in the Fourth Industrial Revolution (pp. 337-344). https://doi.org/10.1007/978-3-030-26528-1_33

Moradlou, B. H., \& Perera, T. (2017). Identification of the barriers in implementation of lean principles in iranian SMEs: Case study approach. Global Journal of Management and 
Business Research, 17(1), 33-41.

Mossman, A. (2009). Why isn't the UK construction industry going lean with gusto? Lean Construction Journal.

Movaghar, E. M. (2016). Identifying the Barriers of Implementing Lean Construction Principals In Developing Countries [MIDDLE EAST TECHNICAL UNIVERSITY]. http://etd.lib.metu.edu.tr/upload/12620522/index.pdf

Nikakhtar, A., Hosseini, A. A., Wong, K. Y., \& Zavichi, A. (2015). Application of lean construction principles to reduce construction process waste using computer simulation: A case study. International Journal of Services and Operations Management, 20(4), 461-480. https://doi.org/10.1504/IJSOM.2015.068528

Nwaki, W. N., \& Eze, C. E. (2020). Lean construction as a panacea for poor construction projects performance. ITEGAM- Journal of Engineering and Technology for Industrial Applications (ITEGAM-JETIA), 6(26). https://doi.org/10.5935/jetia.v6i26.723

Oguntona, O. A., Aigbavboa, C. O., \& Mulongo, G. N. (2019). An assessment of lean construction practices in the construction industry. Advances in Intelligent Systems and Computing, 788, 524-534. https://doi.org/10.1007/978-3-319-94199-8_51

Oke, A., Akinradewo, O., Aigbavboa, C., \& Ndalamba, M. (2021). Challenges to the Implementation of Lean Construction Practices in the South African Construction Industry. In Syed Ahmed, P. Hampton, S. Azhar, \& A. Saul (Eds.), Collaboration and Integration in Construction, Engineering, Management and Technology (pp. 133-137). Springer Nature. https://doi.org/10.1007/978-3-030-48465-1_23

Olamilokun, O. (2015). Investigating Facilitators and Barriers for Adopting Lean Construction Principles in the Nigerian Building Consulting Firms. International Journal of Innovative Research and Development, 4(12), 234-239. http://www.ijird.com/index.php/ijird/article/view/84267

Omotayo, T., \& Kulatunga, U. (2014, April 11). The widening knowledge gap in the built environment of developed and developing nations : Lean and offsite construction in Nigeria and the UK. CIB International Conference on Construction in a Changing World. https://www.irbnet.de/daten/iconda/CIB DC27738.pdf

Otali, M., Oladokun, M. G., \& Anih, P. (2020). Influence of Construction Firm Size on the Level of Adoption of Sustainability Practices in Niger Delta, Nigeria. Baltic Journal of Real Estate Economics and Construction Management, 8(1), 102-118. https://doi.org/10.2478/bjreecm2020-0008

Pallant, J. (2007). SPSS survival manual, 3rd. Edition. McGrath Hill.

Salem, O., Solomon, J., Genaidy, A., \& Minkarah, I. (2006). Lean Construction: From Theory to Implementation. Journal of Management in Engineering, 22(4), 168-175. https://doi.org/10.1061/(asce)0742-597x(2006)22:4(168)

Sarhan, J. G., Xia, B., Fawzia, S., \& Karim, A. (2017). Lean construction implementation in the Saudi Arabian construction industry. Construction Economics and Building, 17(1), 46-69. https://doi.org/10.5130/AJCEB.v17i1.5098

Sarhan, J., Xia, B., Fawzia, S., Karim, A., \& Olanipekun, A. (2018). Barriers to implementing lean construction practices in the Kingdom of Saudi Arabia (KSA) construction industry. Construction Innovation, 18(2), 246-272. https://doi.org/10.1108/CI-04-2017-0033

Sarhan, S., \& Fox, a. (2013). Barriers to Implementing Lean Construction in the UK Construction Industry. The Built \& Human Environment Review, 6, 1-17. http://www.tbher.org/index.php/tbher/article/view/81

Scherrer-Rathje, M., Boyle, T. A., \& Deflorin, P. (2009). Lean, take two! Reflections from the second attempt at lean implementation. Business Horizons, 52(1), 79-88. https://doi.org/10.1016/j.bushor.2008.08.004

Shang, G., \& Sui Pheng, L. (2014). Barriers to lean implementation in the construction industry 
in China. Journal of Technology Management in China, 9(2), 155-173. https://doi.org/10.1108/jtmc-12-2013-0043

Sholanke, A. B., Chen, S. J., Newo, A. A., \& Nwabufo, C. B. (2019). Prospects and challenges of lean construction practice in the building industry in Nigeria: Architects' perspective. International Journal of Innovative Technology and Exploring Engineering, 8(8), 667-673.

Sols, A. (2018). A Comprehensive Approach to Dynamic Project Risk Management. EMJ Engineering Management Journal, $30(2)$

$128-140$. https://doi.org/10.1080/10429247.2018.1450030

Spector, P. E. (1992). Summated rating scale construction: An Introduction: Quantative Applications in the Social Sciences. In SAGE UNIVERSITY PAPERS (Vol. 07, Issue 082).

Srinivasan, N. P., Monisha, K. N., \& Loganathan, M. (2020). A Review on Implementation of Lean Construction Principles in Construction Projects. Test Engineering and Management, 8 (June).

Stern, L. (2010). A Visual Approach to SPSS for Windows: A Guide to SPSS 17.0 (2nd Edition) (2nd ed.).

Tabachnick, B. G., \& Fidell, L. S. (2007). Using Multivariate Statistics 5. In Boston: Pearson Allyn and Bacon. Pearson.

Taherdoost, H., Sahibuddin, S., \& Jalaliyoon, N. (2014). Exploratory factor analysis: Concepts and theory. 2nd International Conference on Mathematical, Computational and Statistical Sciences.

Tezel, A., Koskela, L., \& Aziz, Z. (2018). Lean thinking in the highways construction sector: motivation, implementation and barriers. Production Planning and Control, 29(3), 247-269. https://doi.org/10.1080/09537287.2017.1412522

Tezel, A., \& Nielsen, Y. (2013). Lean Construction Conformance among Construction Contractors in Turkey. Journal of Management in Engineering, 29(3), 236-250. https://doi.org/10.1061/(asce)me.1943-5479.0000145

Wandahl, S. (2014). Lean Construction with or without Lean - Challenges of implementing Lean construction. 22nd Annual Conference of the International Group for Lean Construction: Understanding and Improving Project Based Production, IGLC 2014, 97-108.

Yadav, G., Seth, D., \& Desai, T. N. (2018). Prioritising solutions for Lean Six Sigma adoption barriers through fuzzy AHP-modified TOPSIS framework. International Journal of Lean Six Sigma, 9(3), 270-300. https://doi.org/10.1108/IJLSS-06-2016-0023

Zhang, X., Azhar, S., Nadeem, A., \& Khalfan, M. (2018). Using Building Information Modelling to achieve Lean principles by improving efficiency of work teams. International Journal of Construction Management, 18(4), 293-300. https://doi.org/10.1080/15623599.2017.1382083 